\title{
Correspondence
}

\section{Sea change for plastic pollution}

Scientists, policymakers and the public can learn from LITTERBASE, a newly launched online database of information from 1,300 peer-reviewed publications that provides analysis and visualization of human-generated marine litter worldwide (http://litterbase.org). This comprehensive resource will help to coordinate international action against a lethal form of aquatic pollution.

LITTERBASE shows that almost all of the world's oceans contain litter (represented by yellow dots, pictured; compiled from data in more than 600 peer-reviewed publications). This pollution is crippling and depleting more than 1,300 species through entanglement and ingestion. On a global scale, non-degradable plastic accounts for $73 \%$ of litter in any aquatic habitat. Joint international management action is urgently needed to clean up this waste and to force countries to stop their excessive use and dumping of plastics.

Large stretches of ocean are as yet uncharted with respect to the distribution of marine litter. Still relatively unexplored are the deep ocean floor, the polar regions and the major oceanic frontal systems that shape this pollution. LITTERBASE offers a freely accessible tool for tackling these as well.

Melanie Bergmann, Mine B. Tekman, Lars Gutow Alfred Wegener Institute Helmholtz Centre for Polar and Marine Research, Bremerhaven, Germany. melanie.bergmann@awi.de

\section{Carbon markets: extend, don't limit}

In our view, your headline 'Don't link carbon markets' is poor advice to policymakers (J. Green Nature 543, 484-486; 2017). To cut carbon pollution at the pace and scale that science demands,

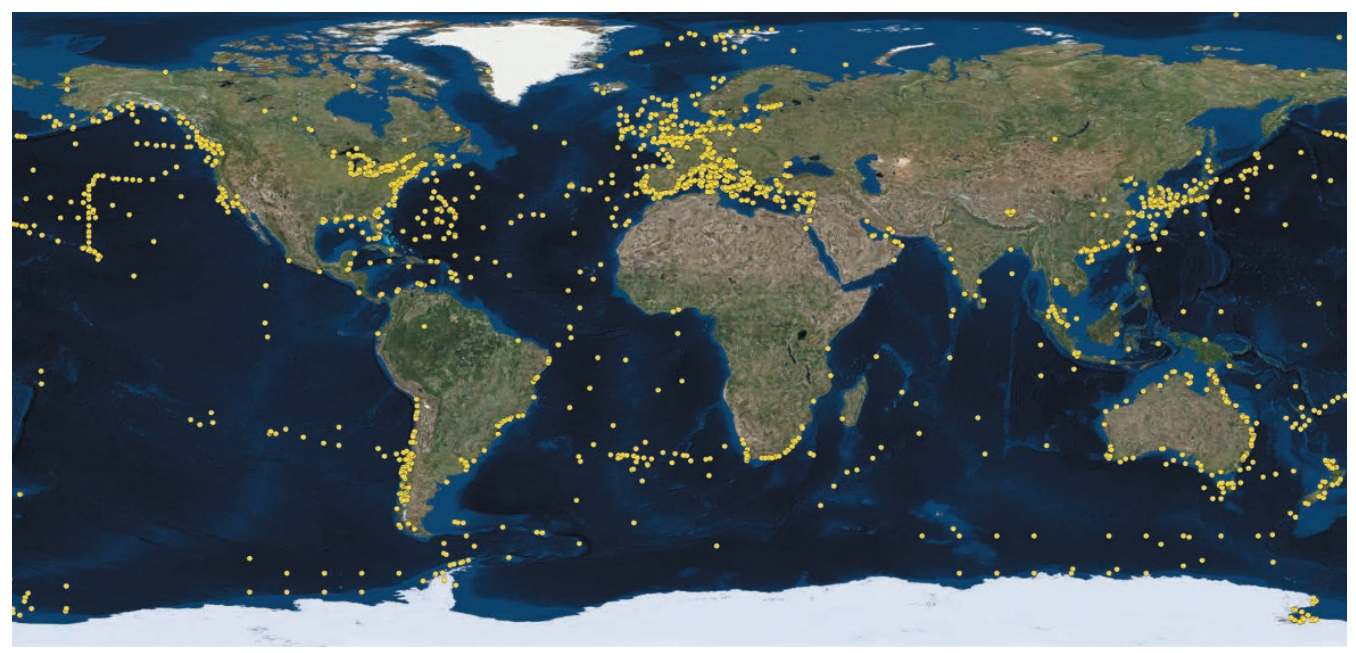

we must create linkages that can tap into the most cost-effective reductions.

Contrary to Jessica Green's claim that trading works only as a closed system, the US capand-trade programme for sulfur dioxide succeeded alongside an assortment of state and federal standards. The fact that sulfur allowances now trade for a few cents is more vindication than failure, given the deep emissions cuts achieved by the programme and subsequent regulations.

As for existing carbontrading schemes, they are meeting their targets - and can be strengthened over time. California passed an ambitious 2030 target into law last year and the European Union is working to improve its system. The Regional Greenhouse Gas Initiative in the northeastern United States has tightened its carbon cap once and is reassessing it with a view to restricting it further.

However, linking markets is not a panacea and requires care. Emissions-trading systems should stand on their own before linking with other compatible systems, and countries involved in trading should adopt common standards and guidelines to ensure environmental integrity. Nathaniel Keohane, Erica Morehouse Environmental Defense Fund, New York, USA. nkeohane@edf.org

\section{Carbon markets: link with caution}

Jessica Green's admonition

to avoid linking carbon

markets is not the consensus among economists and social scientists (Nature 543, 484-486; 2017). This advice seems to misinterpret how carbon-pricing instruments operate.

International trade in goods and services has improved welfare without a central authority to manage quantities and prices. In the same way, a central carbon bank is not a necessary condition for a system of linked carbon markets to achieve their objective of restricting emissions to the selected cap at the lowest possible cost. That said, an institution similar to the World Trade Organization could be useful for addressing market failures, to provide a forum for negotiations and to resolve disputes.

In our view, Green's one-sizefits-all claim that no carbon markets should be linked is too extreme, just as a recommendation to link all carbon markets would be. We need instead to accrue theoretical and empirical evidence for the extra benefits and costs engendered by linking previously isolated carbon markets (see, for example, B. Doda and L. Taschini J. Assoc. Environ. Resour. Econ. http://doi. org/b5pr; 2016).

Baran Doda, Luca Taschini
London School of Economics and Political Science, London, UK. l.b.doda@lse.ac.uk

\section{Teach children to spot fake facts}

I agree that we should train students how to use the scientific method in their everyday lives (Nature 543, 149; 2017 and Nature 543, 150; 2017), but this needs to start much earlier than in college or graduate school. Children in middle school (11-14 years old in the United States) are comparatively more susceptible to fake facts than are university students, and there are many millions more of them.

At California State University, our programmes for training thousands of 11-year-olds in the use of scientific methods were developed in the 1990s with Nobel laureate Francis Crick and have won a US Presidential Award for excellence in science mentoring. The students learn through properly executed, hands-on research.

Similar programmes nationwide would equip citizens to evaluate what goes on every day in a society where the almighty dollar all too often clouds the truth.

Steven B. Oppenheimer California State University, Northridge, California, USA. steven.oppenheimer@csun.edu 